\title{
Real-time RT-PCR detection of Citrus bark cracking viroid (CBCVd) in hops including an mRNA-based internal positive control
}

\author{
Luitgardis Seigner $^{1} \cdot$ Marion Liebrecht $^{1} \cdot$ Linda Keckel $^{1} \cdot$ Katharina Einberger $^{1} \cdot$ Carolin Absmeier $^{1}$
}

Received: 10 January 2020 / Accepted: 27 March 2020 / Published online: 18 April 2020

(c) The Author(s) 2020

\begin{abstract}
Citrus bark cracking viroid (CBCVd), formerly known as pathogen in the genus Citrus and first detected in Slovenian hops in 2014, threatens hop production as it leads to important economic losses. Reduction in yield and quality and even death of the infected plants within a few years are typical observations due to CBCVd infections of hops. The viroid is easily transmitted and spreads rapidly. As it cannot be controlled by plant protection measures, avoiding its introduction into hop gardens and eradicating first centres of infection are of utmost importance. An indispensable prerequisite is a reliable detection method suitable for large-scale routine testing. In this study, the development of primers and probe for real-time RT-PCR for sensitive CBCVd detection is described. To exclude "false negative" results, a nad5 mRNA-based internal positive control was included. To our knowledge, this is the first time such a duplex real-time RT-PCR detection method for CBCVd at least in hops is described. In addition, first method validation data are presented.
\end{abstract}

Keywords Cbcvd · Citrus bark cracking viroid · Duplex RT-PCR · Internal control · Hops · Real-time RT-PCR · Validation

\section{Background}

Viroids are the smallest plant pathogenic particles known. They only consist of an un-encapsidated, circular, singlestranded RNA which forms rods due to intra-molecular base paring. Viroids are highly infectious and can cause significant economic losses in important agricultural and horticultural crops. During cultivation operations, viroids are readily transmitted, spread within a field and are disseminated from one place of production to another. Viroidspecific small RNAs (sRNAs) emerging after infection are assumed to affect the host metabolism and lead to symptom expression by post transcriptional gene silencing (PTGS) or RNA silencing of host mRNAs (Qi and Ding 2003; Gas et al. 2007; Voinnet 2008).

At present also hop production is threatened by viroid infections which may lead to detrimental reduction in yield and quality and thus affect hop growers and brewers as well. Eastwell and Nelson (2007) reported of serious damage

Luitgardis Seigner

Luitgardis.Seigner@LfL.bayern.de

1 Bavarian State Research Center for Agriculture, Institute for Plant Protection, Lange Point 10, 85354 Freising, Germany in hops (Humulus lupulus L., Cannabaceae) caused by the Hop stunt viroid (HpSVd). In 2007, a similar disease was observed in Slovenian hop gardens which resulted in severely stunted hop plants. Symptoms were comparable to those known from HpSVd infections, but disease progress was much faster and in contrast to $\mathrm{HpSVd}$ stunting plants died off within 3-5 years (Jakse et al. 2015). Using highthroughput sequencing deep sequencing, Jakse et al. (2015) identified the causal agent of this new devastating and fast spreading disease as Citrus bark cracking viroid (CBCVd; syn. Citrus viroid IV, CVd IV), a member of the family Pospiviroidae. This was the first time CBCVd which previously was only known as minor pathogen in the genus Citrus (Duran-Vila et al. 1988) was reported in hops. The initial outbreak took place in a hop garden where in former times infected citrus material was deposited and which is assumed to be source of infection (EPPO Reporting Service 2015).

CBCVd is sap-transmissible and can be transmitted by contaminated tools and machinery which makes it a dangerous pathogen, especially in hop production where regular cultivation measures are needed. As opposed to citrus CBCVd infections spread rapidly in hop gardens, mainly along plant rows. As hop cultivars are propagated vegetatively by root cuttings, planting material derived from infected mother plants is a dangerous source for 
dissemination of CBCVd over long distances. Chopped hop waste taken to the hop yard as part of a sustainable plant production is a further crucial factor for spreading CBCVd. Moreover, there may be a risk arising from the application of biogas fermentation residues and compost containing infected citrus and hop material. CBCVd like any other viroid cannot be controlled by using plant protection products. Phytosanitary actions to prevent introduction and further spread of the infection are the only way to counteract these dangerous pathogenic particles. In this context, the use of tested plant material, the monitoring for initial cases of infection and the eradication of first hotspots are indispensable. An essential prerequisite for controlling CBCVd is reliable detection methods suitable for large-scale routine testing. Keeping all this in mind, as early as in 2013, when the first reports of CBCVd occurrence in hops were published, conventional RT-PCR for CBCVd detection was established at the Bavarian State Research Center for Agriculture and CBCVd was included in the HpSVd monitoring program conducted each year. HpSVd monitoring started in 2008 when the occurrence of $\mathrm{HpSVd}$ was reported in the USA (Nelson and Eastwell 2007) and its harmful effects became evident. The ongoing monitoring comprises all German hop production areas, but is mainly focussed on breeding material, mother plants for propagation and plants from commercial hop yards in the Hallertau, the world's largest hop growing region. In 2016, a real-time RT-PCR was developed for CBCVd. From 2017 onwards, all samples were tested using this new technique. To ensure reliable results and to exclude false negatives, an internal mRNA-based positive control (IPC) targeting NADH dehydrogenase subunit 5 mRNA is run in a duplex reaction along with the $\mathrm{CBCVd}$-specific primers and probe (Menzel et al. 2002; Botermans et al 2013). To our knowledge, this is the first time such a duplex real-time RT-PCR is used for CBCVd detection at least in hops. The present paper describes the method and provides first results obtained from method validation.

\section{Materials and methods}

\section{RNA extraction RNA from hop leaves}

For RNA extraction, the RNeasy Plant Mini Kit (QIAGEN, Hilden, Germany) was utilised. $500 \mathrm{mg}$ plant material (fresh or stored at about minus $80^{\circ} \mathrm{C}$ ) was ground in extraction bags $(12 \mathrm{~cm} \times 15 \mathrm{~cm})$ using a hand roller or Homex 6 (Bioreba, Reinach, Switzerland) immediately after $4.5 \mathrm{ml}$ RLC extraction buffer had been added. The detailed RNA extraction procedure is described in the EPPO Diagnostic protocols, PM 7/33 for Potato spindle tuber pospiviroid (Anonymous 2004). Material from negative and positive hop leaves was extracted as negative and positive extraction control, respectively, simultaneously with the samples.

\section{Real-time RT-PCR}

For CBCVd detection, new primers and probe were developed by using SIGMA-ALDRICH OligoArchitect ${ }^{\text {TM }}$ Online (see results). Primers and probe sequences for IPC were according to Menzel et al. (2002) and Botermans et al. (2013). Sequences for primers and TaqMan ${ }^{\circledR}$ probes were synthesized by Eurofins (Ebersberg, Germany), and final concentrations are given in Table 1. Viroid and IPC detection were run in the same tube in order to exclude false negative results from unsuccessful RNA extraction, failed reverse transcriptase reaction or PCR and from pipetting errors. $2.22 \mu \mathrm{l}$ RNA were added to the reaction mix to obtain a total reaction volume of $22.22 \mu \mathrm{l}$. RNA was tested undiluted and 1:10 diluted in water to control for any RT-PCR inhibition by hop endogenous compounds. In each real-time RT-PCR run beside samples and extraction controls water was tested as negative control. For real-time RT-PCR, the Bioline SensiFast Probe No-ROX One-Step Kit (BioCat GmbH, Heidelberg, Germany) was used. The cycling parameters were: $48^{\circ} \mathrm{C}$ for $30 \mathrm{~min}$ for the reverse transcriptase reaction, $95^{\circ} \mathrm{C}$ for $10 \mathrm{~min}$ to activate the hot start polymerase, followed by 50 cycles $95^{\circ} \mathrm{C}$ for $15 \mathrm{~s}$ for denaturation and $60^{\circ} \mathrm{C}$ for $60 \mathrm{~s}$ for annealing and primer extension. Real-time RT-PCR was
Table 1 Primers and probes used for CBCVd and IPC

\begin{tabular}{llc}
\hline Primer/probe & Sequences $5^{\prime} \rightarrow 3^{\prime}$ and probe labelling & $\begin{array}{l}\text { Final con- } \\
\text { centration } \\
(\mu \mathrm{M})\end{array}$ \\
\hline CBCVd-qPCR-F & GGAACAGGAGCTCGTCTC & 0.3 \\
CBCVd-qPCR-R & GTCCCGCAGAGAAATTCC & 0.3 \\
CBCVd-qPCR-P & FAM-CATCGCTGGCTCCACATCCG-BHQ1 & 0.1 \\
nad5-F & GATGCTTCTTGGGGCTTCTTGTT & 0.3 \\
nad-R & CTCCAGTCACCAACATTGGCATAA & 0.3 \\
nad5-P & HEX-AGGATCCGCATAGCCCTCGATTTATGTG-BHQ1 & 0.2 \\
\hline
\end{tabular}


run in the CFX96 Touch Real-Time PCR Detection System (BIO-RAD). Results were analysed using the BIO-RAD CFX Manager ${ }^{\mathrm{TM}}$ Software employing baseline subtracted curve fit. Cq threshold values for differentiation between "positive" and "negative" results were not applied as in negative extraction controls and no template real-time RT-PCR controls no amplification was observed.

\section{CBCVd plasmid standard}

A CBCVd plasmid standard synthesised by Eurofins (Ebersberg, Germany) was developed for method validation and taken as positive reaction control. The RT-PCR product obtained with the CBCVd specific primers according to Ito et al. (2002) was integrated at the multiple cloning site (MCS) of the plasmid pexA2 and the plasmid linearized by SaII digestion. A dilution series in water using the plasmid solution delivered by the supplier was prepared to obtain the plasmid stock solution with plasmid copy numbers of about $4 \times 10^{6}$ in a volume of $2.22 \mu$ l. This stock solution was aliquoted into DNA LoBind Tubes (Eppendorf AG, Hamburg, Germany) and stored at about $-20^{\circ} \mathrm{C}$. For each RT-PCR run, another aliquot of the " $4 \times 10^{6}$ stock solution" was used and a tenfold plasmid standard dilution series prepared resulting in plasmid copy numbers of 300.000 to 30 in a volume of $2.22 \mu \mathrm{l}$ which is equivalent to the amount of RNA added to the real-time PCR tube.

\section{Results}

\section{Design of primers and probe for CBCVd}

New primers and a new TaqMan ${ }^{\circledR}$ probe were developed for $\mathrm{CBCVd}$ detection. For CBCVd originating from hops, only a single sequence was available which was obtained from sequencing an RT-PCR amplicon obtained with primers published by Ito et al. (2002). CBCVd infected material was kindly provided by Sebastjan Radišek, Slovenian Institute for Hop Research and Brewing, Plant Protection Department, Diagnostics Laboratory. The newly designed primers and probe were selected to achieve a $100 \%$ match to the hop sequence and to coincide to a large extent with 30 sequences of CBCVd isolates from citrus or clones listed in GenBank in order to detect possible other isolates or variants (Accession nos. AB054633.1, AB054634.1, AB054635.1, AJ630359.1, AJ630360.1, AJ630361.1. GQ260216.1, HM042742.1, HM042743.1, HM042744.1, HM042745.1, HM042746.1, HM042747.1, HM042748.1, HM042749.1, JN903762.1，JN903763.1，JN903764.1，JN903765.1, JN903766.1, JN903767.1, JX259418.1, JX259419.1, JX259420.1, JX259421.1, JX259422.1, KM211546.1, KM211547.1, KT725633.1, X14638.1). The sense primers showed $100 \%$ identity in 15 cases, and the reverse primer fits the $\mathrm{CBCVd}$ sequence in 26 and the probe in 16 cases. Primer and probe binding sites of accessions which showed mismatches differed in only one position from the $\mathrm{CBCVd}$ isolate from hops. Primer mismatches were located towards the 5'-end which is less critical with regard to primer elongation during PCR, and probe mismatches were at nucleotide position 3 of the $5^{\prime}$ end (Fig. 1).

\section{Analytical sensitivity and test repeatability}

Four real-time RT-PCR runs were performed to evaluate the plasmid standard-based detection of CBCVd cDNA. In the first real-time RT-PCR run, three parallel plasmid standard dilution series (in water) obtained from one stock solution (app. $4 \times 10^{6} \mathrm{CBCVd}$ cDNA copies/2.22 $\mu$ ) were tested. Each dilution was tested in two replicates. In two of these three dilution series, the lowest copy number detected was 30 copies in the PCR tube; repeatability in each dilution was $100 \%$; in the third dilution series, the highest copy number detected was 300 in the PCR tube with one positive out of two replicates. PCR efficiency determined within the linear range of reaction was app. $94 \%$ in each of the three dilution series (each with an $R^{2} 0.999$ ), and the Cq values (Bustin et al. 2009) were between 21.1 for 300,000 copies and 37.76 for 30 copies of CBCVd cDNA. In the second real-time RTPCR run, one single plasmid standard dilution series was prepared from a further stock solution, and each dilution was tested in four replicates. Copy numbers up to and including 3000 per tube were detected in all four replicates, whereas 300 copies per tube were only detected in two of the four

\section{CCGGGGAAATCTCTTCAGACTCGTCGAGGGGAGGGCGCCGCGGATCACTGGCGTCCAGCACCGGA} ACAGGAGCTCGTCTCCTTCCTTCCATCGCTGGCTCCACATCCGATCGTCGCTTCTTCCTTCGCGACCT GAGAAAGAAACTACCCGGTGGATACAACTCTTGGGTTGTTCCTCCCAGGCTTGTTAAATAAAATGG CCCGCTTTTGAGACCCCTCTGGGGAATTTCTCTGCGGGACCAAATAAAAACAGCTTGAGGAGGGAA CATACCTGAAGAGGGATCC

Fig. 1 Sequence of the Slovenian CBCVd strain obtained from S. Radišek. Grey shaded: conventional RT-PCR primer binding sites according to Ito et al. (2002); underlined: binding sites for the newly designed primers and TaqMan® probe for real-time RT-PCR 
parallels; 30 copies per tube could not be detected in this run. PCR efficiency in the linear range of reaction in this run was app. $109 \%\left(R^{2} 0.972\right), \mathrm{Cq}$ values ranged from 24.5 for 300,000 copies per tube to 34.73 for 300 copies. In the third real-time RT-PCR, once again one plasmid standard dilution series prepared from another stock solution was tested in four replicates. This time positive results were obtained in all dilutions from 300,000 up to and including 30 copies with a repeatability of $100 \%$ (Cq values between 19.37 for 300,000 copies and 34.11 for 30 copies, efficiency $92.8 \%, R^{2}$ 0.998). For the forth real-time RT-PCR run, a CY5-labelled CBCVd-specific probe instead of the FAM-labelled probe was used in order to assess test robustness with respect to labelling. A further aim of this modification was to prepare a triplex real-time RT-PCR in which beside CBCVd and IPC the Hop stunt viroid (HpSVd) could be detected in the same tube combining a FAM-labelled HpSVd probe with a CY5-labelled CBCVd and a HEX-labelled IPC probe. Also with the CY5-labelled probe $\mathrm{CBCVd}$ detection was possible from 300,000 copies down to and including 30 copies in both of two replicates (efficiency in the linear range of reaction $\left.102.7, R^{2} 0.998\right)$.

To elucidate the test performance with the naturally infected hop material, RNA was isolated from leaves sampled at the same time of three CBCVd infected hop plants (Humulus lupulus L.) of the same cultivar (Mandarina Bavaria) grown in the same hop garden. Each RNA was tenfold diluted in RNA obtained from a CBCVd negative hop plant up to a maximum dilution of 1:100,000. Three replicates of each dilution were tested with real-time RT-PCR (Fig. 2). With all three samples, the 1:100,000 dilution was the lowest dilution in which $\mathrm{CBCVd}$ could be detected with $\mathrm{Cq}$ values of about 37-38 and a repeatability of 50-67\% ( $=1-2$ positives out of 3 parallels). CBCVd was detected to $100 \%$ in dilutions up to and including 1:1000 and to $89 \%$ in dilution 1:10,000. The efficiency of the real-time RT-PCR

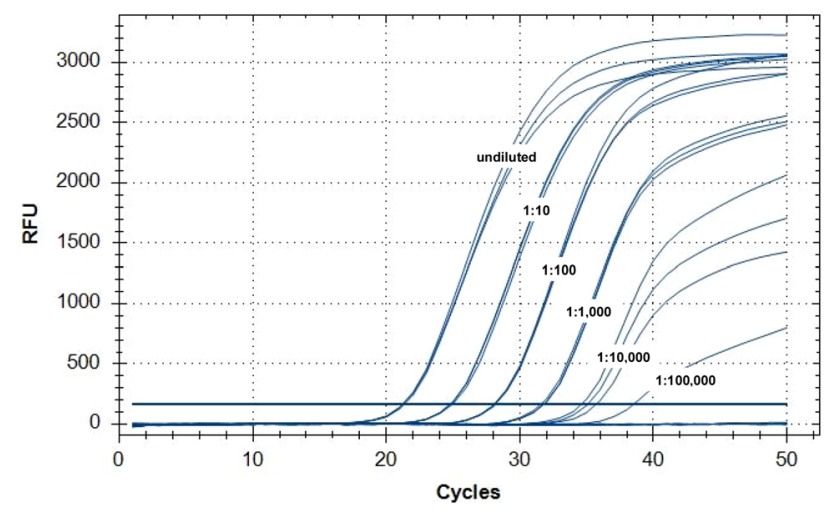

Fig. 2 Real-time RT-PCR amplification of CBCVd RNA. RNA dilutions in negative hop RNA ranged up to $1: 100,000$. RFU relative fluorescence units determined in the linear range of reaction with the three hop samples was app. $95 \%\left(R^{2}=0.9984\right), 108 \%\left(R^{2}=0.9912\right)$ and $113 \%\left(R^{2}=0.9877\right)$, respectively. The IPC was detected with $\mathrm{Cq}$ values between 17 and 21, and no false negatives were observed. Testing the three samples mentioned above in parallel with real-time RT-PCR and conventional RT-PCR using primers according to Ito et al. (2002) (data not shown) demonstrated that real-time RT-PCR is more sensitive: the highest dilution 1:100,000 was tested positive in each realtime RT-PCR run, whereas using conventional RT-PCR the highest dilution in which CBCVd was detected was between $1: 100$ and $1: 10,000$ with a repeatability of $50-67 \%(=1-2$ positives out of 3 parallels).

\section{Discussion}

\section{CBCVd plasmid standard}

The CBCVd plasmid standard revealed that the newly developed primers and probe are well suited for a sensitive real-time PCR detection of CBCVd with PCR efficiencies between 93 and $110 \%$. The lowest CBCVd cDNA copy number detected was 30 copies in the RT-PCR tube, but this low limit of detection was not reached in each PCR run. A repeatability of $100 \%$ was achieved with copy numbers up to and including 3000 copies in the reaction tube. Despite the fact that the plasmid standard does not allow for the control of the reverse transcriptase reaction, this kind of standard is of great advantage in routine testing as the availability of CBCVd-infected reference material is limited. Such a welldefined standard also enables to compare different PCR runs in routine diagnostics as variabilities in the performance between different test setups and runs cannot be excluded. A possible way out of the dilemma that the plasmid standard does not provide an estimation of the efficiency of the reverse transcriptase reaction are RNA controls produced by in vitro transcription of cDNA, but for routine testing the application of such elaborate RNA standards would be too expensive.

\section{Testing of naturally infected plant material}

The newly developed primers and probe for CBCVd detection demonstrated very good performance also when testing naturally infected hop plants. RNA isolated from infected hop leaves and diluted in negative hop RNA up to 1:100,000 was tested positive although with a repeatability of lower than $100 \%$ in the higher dilutions and with high Cq values. Notwithstanding the fact that in our experiments amplification in negative controls was not observed, in routine testing in order to rule out false positives with certainty samples showing high $\mathrm{Cq}$ values $(>30)$ should be retested 
or resampling should be performed later when viroid concentration will have increased. The test is robust, since even in the presence of the complex matrix of hops with various endogenous compounds which might interfere or even inhibit RT-PCR very low concentrations of CBCVd could be detected. The sensitivity of the real-time RT-PCR exceeds that of conventional RT-PCR at least by a factor of 10. The consistent performance of the IPC with no single failure in all our tests proved that the RNA extraction procedure applied delivers RNA highly suitable for CBCVd real-time RT-PCR detection. This is at least true when extracting leaf material. Recent experiments showed that the RNA extraction method described here is also suitable for CBCVd detection in woody hop bines and detection of Hop latent viroid in hop cones. Further efforts are needed for reliably detection of viroids in more complex matrices, e.g. samples from silage and biogas fermentation. A pitfall in routine diagnostic could be that the confirmation of a positive real-time RT-PCR result with high $\mathrm{Cq}$ values by conventional RT-PCR and subsequent sequencing cannot be achieved due to the lower analytical sensitivity of the conventional RT-PCR. Such a confirmation may be necessary in cases of new emergence of CBCVd in a defined region or hop garden. Also for answering practical questions like viroid persistence during silaging or biogas fermentation or for isolate characterisation sequencing of the whole viroid genome may be needed. In this context, an adaptation of the RNA extraction procedure and conventional RT-PCR to special matrices other than leaves should be subject of future research activities.

Acknowledgements Open Access funding provided byProjekt DEAL. We would like to thank Dr. Sebastjan Radišek, Slovenian Institute for Hop Research and Brewing Žalec, Slovenia, for providing CBCVd infected plant material and CBCVd RNA and fruitful discussions. Thanks go to Dr. Elisabeth Seigner, LfL, for improving this manuscript and providing practical advice. We are grateful to the Bayerisches Staatsministerium für Ernährung, Landwirtschaft und Forsten for financial support.

Funding This study was funded by the Bayerisches Staatsministerium für Ernährung, Landwirtschaft und Forsten.

\section{Compliance with ethical standards}

Conflict of interest The authors declare that they have no conflict of interest.

Open Access This article is licensed under a Creative Commons Attribution 4.0 International License, which permits use, sharing, adaptation, distribution and reproduction in any medium or format, as long as you give appropriate credit to the original author(s) and the source, provide a link to the Creative Commons licence, and indicate if changes were made. The images or other third party material in this article are included in the article's Creative Commons licence, unless indicated otherwise in a credit line to the material. If material is not included in the article's Creative Commons licence and your intended use is not permitted by statutory regulation or exceeds the permitted use, you will need to obtain permission directly from the copyright holder. To view a copy of this licence, visit http://creativecommons.org/licenses/by/4.0/.

\section{References}

Anonymous (2004) Diagnostic protocols for regulated pests-PM 7/33: potato spindle tuber pospiviroid. EPPO Bull 34:257-269

Botermans M, van de Vossenberg BTLH, Verhoeven JThJ, Roenhoerst JW, Hooftman M, Dekter R, Meekes ETM (2013) Development and validation of a real-time RT-PCR assay for generic detection of pospiviroids. J Virol Methods 187:43-50

Bustin SA, Benes V, Garson JA, Hellemans J, Huggett J, Kubista M, Mueller R, Nolan T, Pfaffl MW, Shipley GL, Vandesompele J, Wittwer CT (2009) The MIQE guidelines: minimum information for publication of quantitative real-time PCR experiments. Clin Chem 55(4):611-622

Duran-Vila N, Roistacher CN, Rivera-Bustamante R, Semancik JS (1988) A definition of citrus viroid groups and their relationship to the exocortis disease. J Gen Virol 69:3069-3080

Eastwell KC, Nelson ME (2007) Occurrence of viroids in commercial hop (Humulus lupulus L.) production areas of Washington State. Plant Manag Netw 8(1):1-8

EPPO Reporting Service (2015) Citrus bark cracking viroid is causing 'severe hop stunt disease' in Slovenia: addition to the EPPO Alert List. EPPO Reporting Service no. 06

Gas ME, Hernández C, Flores R, Daròs JA (2007) Processing of nuclear viroids in vivo: an interplay between RNA conformations. PLoS Pathog 3:1813-1826

Ito T, Ieki H, Ozaki K, Iwanami T, Nakahara K, Hataya T, Ito T, Isaka M, Kano T (2002) Multiple citrus viroids in citrus from Japan and their ability to produce exocortis-like symptoms in citron. Phytopathology 92(5):542-547

Jakse J, Radišek S, Pokorn T, Matousek J, Javornik B (2015) Deepsequencing revealed Citrus bark cracking viroid (CBCVd) as a highly aggressive pathogen on hop. Plant Pathol 64(4):831-842

Luigi M, Faggioli F (2013) Development of a quantitative real-time RT-PCR (qRT-PCR) for the detection of Hop stunt viroid. Eur J Plant Pathol 137:231-235

Menzel W, Jelkmann W, Mais E (2002) Detection of four apple viruses by multiplex RT-PCR assays with coamplification of plant mRNA as internal control. J Virol Methods 99:81-92

Nelson M, Eastwell K (2007) Occurrence of viroids in commercial hop (Humulus lupulus L.) production areas of Washington State. Plant Health Prog Plant Manag Netw 8(1):1-8

Qi Y, Ding B (2003) Inhibition of cell growth and shoot development by a specific nucleotide sequence in a noncoding viroid RNA. Plant Cell 15:1360-1374

Voinnet O (2008) Use, tolerance and avoidance of amplified RNA silencing by plants. Trends Plant Sci 13:317-328

Publisher's Note Springer Nature remains neutral with regard to jurisdictional claims in published maps and institutional affiliations. 